\begin{tabular}{|l|l|l|l|l|l|}
\hline MUNIBE Antropologia-Arkeologia & $n^{\circ} 68$ & $237-249$ & DONOSTIA & 2017 & ISSN $1132-2217 \cdot$ elSSN $2172-4555$ \\
\hline
\end{tabular}

\title{
Los Villares (Fresno Alhándiga, Salamanca): un complejo termal junto a la Vía de la Plata(1)
}

\author{
Los Villares (Fresno Alhándiga, Salamanca): \\ an thermal complex next to the Via de la Plata
}

PALABRAS CLAVES: Salamanca; asentamiento romano; termas; opus signinum; mosaico. GAKO-HITZAK: Salamanca; erromatarren kokalekua; termak; opus signinum; mosaikoa. KEY WORDS: Salamanca; roman site; thermal complex; opus signinum; mosaic.

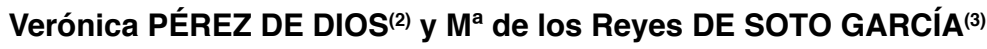

\section{RESUMEN}

La realización de varios sondeos polínicos en el yacimiento de Los Villares (Fresno Alhándiga, Salamanca) en julio de 2015 deparó el hallazgo de un yacimiento romano de tipología indeterminada no catalogado que presenta, al menos, un pavimento musivo. La escasa profundidad a la que se encontró el mosaico (20-30 cm de la superficie de cultivo) motivó la realización de una intervención arqueológica de urgencia en el enclave para tratar de delimitar la extensión de dicho pavimento y confirmar la posible existencia de otros restos de notable entidad. Los trabajos arqueológicos han puesto de manifiesto el elevado grado de arrasamiento de buena parte del yacimiento aunque, han permitido recuperar parte del complejo termal. En este artículo se describen los trabajos realizados durante la campaña de excavaciones de 2015, aportando datos inéditos sobre el complejo termal en el que se ha localizado un hypocaustum, un pavimento de opus tesselatum y dos de opus signinum.

\section{LABURPENA}

Los Villareseko (Fresno Alhándiga, Salamanca) aztarnategian zenbait zundaketa poliniko eginda, 2015eko uztailean, zehaztu gabeko eta katalogatu gabeko tipologiako aztarnategi erromatarra topatu zen, eta gutxienez, mosaiko-zoladura bat du. Mosaikoa sakonera txikian topatu zenez (lantze-gainazaletik 20-30 cm-ra), urgentziazko esku-hartze arkeologikoa egin zen tokian, zoladura horren hedapena mugatzeko eta antzeko garrantzia duten beste hondakin batzuk badauden egiaztatzeko. Lan arkeologikoek agerian utzi dute aztarnategiaren zati handi bat oso suntsituta dagoela, baina konplexu termalaren zati bat berreskuratu ahal izan da. Artikulu honetan, 2015eko indusketen kanpainan egindako lanak deskribatzen dira, eta konplexu termalari buruzko datu argitaragabeak eskaintzen dira. Bertan topatu dira hypocaustum bat, opus tesselatum zoladura bat eta bi opus signinum zoladura.

\section{ABSTRACT}

Several pollen analyses at the archaeological site of Los Villares (Fresno Alhándiga, Salamanca) have been realized in July 2015. These studies show the existence of a Roman site with indeterminate typology and uncatalogued, that including a mosaic floor. The mosaic was nearly the surface (20-30 cm of it) which conducting an emergency operation at the site. The main aim of this operation was to define the extent of the pavement and confirm the existence of others interesting remains. Archaeological studies have revealed a high degree of razing on the site complex. On the other hand, excavations have recovered part of the thermal complex. So that, in this article we describe the 2015 excavation campaign, taking into a count all the new data discovered on the thermal complex, as the hypocaustum location, a pavement of opus tesselatum and two opus signinum. The distribution of the rooms of archaeological site of Los Villares indicate that the mosaic room could have had the function of tepidarium and the adjacent rectangular room could have had the function of frigidarium and caldarium. In the geometric pavement of opus tesellatum, figurative elements such as fish, dolphins or craters are also visible. The importance of the archaeological site is not only related to the discovery of a new geometric mosaic but also to the increase in possibilities of future research of a settlement located next to the Via de la Plata.

\footnotetext{
(1) Este trabajo se enmarca dentro del proyecto de tesis doctoral "Poblamiento romano y altomedieval en el valle medio del río Tormes" financiado por la Universidad de Salamanca, del proyecto de excavación arqueológica "Los Villares" (Fresno Alhándiga) financiado por la Junta de Castilla y León y del Grupo de Investigación Reconocido ATAEMHIS (Universidad de Salamanca). Asimismo se encuadra en el proyecto I+D+I subvencionado por el Ministerio de Ciencia e Innovación (HAR2013-43701-P) "Dinámicas socio-ecológicas, resiliencia y vulnerabilidad en un paisaje de montaña: el Sistema Central (9000 cal. BC-1850 cal. AD)" (DÉSIRE). Finalmente agradecer el apoyo de todas las personas que han colaborado desinteresadamente en las tareas de excavación; sin ellas este proyecto no podría haberse llevado a cabo; la comprensión y amabilidad del propietario de los terrenos Julio Pérez Tabernero y del agricultor Paco Boyero y las correcciones y comentarios al artículo de Enrique Ariño Gil y Luis R. Menéndez Bueyes.

(2) Universidad de Salamanca. Dpto. de Prehistoria Historia Antigua y Arqueología. C/Cervantes s/n 37002 Salamanca, veropdd@usal.es.

(3) Asistente Técnico Museo Nacional del Prado. Paseo del Prado, s/n, 28014 Madrid, reyesdesoto@usal.es.
} 


\section{1.- INTRODUCCIÓN}

Durante la campaña de 2015 los trabajos de prospección arqueológica llevados a cabo en un área no catalogada arqueológicamente del término municipal de Fresno Alhándiga nos permitieron documentar un yacimiento inédito adscrito a cronología romana. En el mes de julio, la realización de tres sondeos polínicos en el yacimiento de Los Villares deparó el hallazgo de un pavimento musivo geométrico con representaciones figuradas de peces y delfines localizado a tan sólo 20 $\mathrm{cm}$ de la superficie de cultivo. La escasa profundidad a la que se encontraba el pavimento, la continuación de este fuera de los límites establecidos en el sondeo polínico -cata de un metro por un metro- y los numerosos fragmentos de mosaico y teselas aisladas localizadas en prospección sobre la superficie del yacimiento favorecieron la realización de una intervención arqueológica de urgencia que pudiera determinar el grado de alteración de pavimento. Mediante un convenio, la Junta de Castilla y León y la Universidad de Salamanca se propusieron la delimitación del nuevo mosaico, el estudio del mismo y la documentación de otros restos de similares características.

Los trabajos de excavación arqueológica llevados a cabo entre octubre y diciembre de ese mismo año por un equipo de arqueología de la Universidad de Salamanca, han puesto de manifiesto el elevado grado de arrasamiento al que se ha visto expuesto el yacimiento por las continuas labores agrícolas, pero han permitido recuperar parte de un complejo termal en el que es posible diferenciar una habitación con pavimento musivo, dos estancias de menor tamaño de opus signinum y un hypocaustum en perfecto estado de conservación. La intervención ha sacado a la luz buena parte de un yacimiento de cronología romana de similares características a los hallados en otras áreas de la provincia de Salamanca como Los Villares (Forfoleda), La Mina (Pedroso de la Armuña), Aldealama (La Vellés) (Ariño, 2006), Vega de Santa Bárbara (Alconada) (STRATO, 2003; de Soto, 2015) o La Vega (Villoria y Villoruela) (García Figuerola y Angoso, 1986; Regeras y Pérez, 1997: 51-60).

Geográficamente, el yacimiento de Los Villares se ubica en el término municipal de Fresno Alhándiga (Salamanca), en terrenos fértiles de la vega del arroyo Alhándiga, afluente del curso medio del río Tormes. El valle del Tormes se define como una unidad geográfica natural que presenta unas características geomorfológicas, topográficas y bioclimáticas óptimas que otorgan a los asentamientos de la zona una localización inmejorable por gozar de gran salubridad ambiental y cercanía a los recursos hídricos. Sin lugar a dudas, estas condiciones favorables fueron aprovechadas por los pobladores del pasado para establecer sus asentamientos antes incluso de época romana, pues en las inmediaciones del yacimiento objeto de nuestro estudio se han localizado restos de túmulos megalíticos -dólmenes El Teriñuelo y Los Torrejones- que dilatan la ocupación del lugar desde época calcolítica (Maluquer, 1956: 63). En lo referente al paleoambiente, cabría señalar que los estudios realizados en otras áreas cercanas del Sistema Central ratifican la existencia de cambios climatológicos abruptos acaecidos en época romana y tardoantigua. Además, las fuentes clásicas y el registro paleoambiental coinciden en confirmar la aparición de un modelo agropecuario a partir de época Bajo Imperial (Blanco, López y Merino, 2009 y Blanco y López, 2013).

\section{LOS ASENTAMIENTOS RURALES EN LA PROVINCIA DE SALAMANCA}

En época romana, los agrónomos manifiestan que la elección del emplazamiento no solo estaría supeditada a las condiciones medioambientales que favorecerían la explotación de los recursos agroganaderos (Cat. Agri. I 1.2.), sino también a la proximidad de uillas, uicus y mansio a las vías de comunicación. Tradicionalmente, la mayor parte de los asentamientos rurales de cronología romana han sido categorizados como uillas, lugares que no sólo han de ser entendidos como centros de explotación de los recursos agrarios, sino también como áreas residenciales de descanso y recreo en las que existían espacios dedicados al ocio (Gorges, 1979; Chavarria, 2006: 18-25, Fornell, 2005: 6-7). Junto a ellas, destacarían los vicus, asentamientos abiertos de cierta entidad que se caracterizaban por tener una trama mínimamente urbana y por depender de las ciudades cercanas (Pérez Losada, 1996: 190 y Pérez Losada, 2002: 34) y los asentamientos ligados a red viaria: mansiones, mutationes y stationes (Núñez y Sáenz, 2005: 189-190). Desde el punto de vista historiográfico las diferencias entre mansiones, mutationes y stationes son prácticamente imperceptibles si no se dispone de fuentes clásicas o excavaciones de cierta entidad que permitan diferenciar el carácter del emplazamiento (Fanjul, Menéndez y Álvarez, 2005: 187; Núñez y Sáez, 2005: 189-190; Núñez y Saiz, 2009; France y Nelis-Clement, 2014: 11-15).

La escasez de referencias en las fuentes literarias clásicas al territorio meseteño ha dificultado notablemente la comprensión del desarrollo del mundo rural romano de la provincia salmantina. Pese a ello, en las dos últimas décadas el conocimiento de la organización y la explotación territorial en época romana y tardoantigua ha experimentado una notable transformación ligada al auge de las intervenciones arqueológicas y a los estudios realizados desde el Departamento de Prehistoria, $\mathrm{H}^{\mathrm{a}}$ Antigua y Arqueología de la Universidad de Salamanca (Ariño y Rodríguez Hernández, 1997; Ariño et alii., 2002; Ariño et alii., 2004-2005; Ariño, 2006; Pérez de Dios, 2014; de Soto García, 2015; Ariño et alii., 2015; Ariño y de Soto, 2016). Los estudios centrados en el territorio controlado desde la ciudad de Salamanca, el denominado ager Salmanticensis, han proporciona- 
do información sobre el hábitat de la zona más cercana a esta ciudad en época romana y tardoantigua. El aumento de prospecciones intensivas, como la llevada a cabo en la zona de La Armuña (Salamanca); de prospecciones extensivas, como las del ager Salmanticenses, (Ariño y Rodríguez, 1997; Ariño, 2006) Valle del Alagón y Sierra de Francia (Ariño, Barbero y Díaz, 2004) y los trabajos de excavación llevados a cabo en los yacimientos de San Pelayo (Aldealengua) (Dahí Elena, 2007) y Saelices (Saelices el Chico) (Pérez et alii., 1997; Martín y Hernández, 1997; Martín, 2007) han aportado numerosos datos para comprender la evolución del poblamiento en nuestra zona de estudio (García Figuerola, 1989; EXCAR, 1991-1992; Alonso y Ariño, 2001). Asimismo, el estudio del medio físico ligado a la palinología (Blanco, López y Merino, 2009) y, sobre todo, el análisis tipológico de los materiales arqueológicos hallados en los trabajos de campo nos ha permitido identificar varios modelos de poblamiento rural característicos del mundo romano, siendo los más representativos del paisaje salmantino los establecimientos agroganaderos de segundo orden que, podríamos denominar granjas, y las uillas (Ariño, 2006: 324-325). En base a los restos arqueológicos hallados hasta el momento, el paisaje romano salamantino podría identificarse con un poblamiento rural disperso conformado por numerosos asentamientos agroganaderos de pequeño tamaño cuyas funciones serían básicamente productivas y, unas estructuras de mayor envergadura, las uillas, en las que también queda patente la funcionalidad residencial.

\subsection{Evolución del poblamiento rural en la pro- vincia de Salamanca}

La dificultad de realizar una síntesis evolutiva del poblamiento romano en la provincia de Salamanca viene dada por la parcialidad de los contextos arqueológicos y la escasez de referencias en las fuentes. Aunque la romanización de la actual provincia salamantina se produjo en época temprana, los yacimientos adscritos a esta primera fase de ocupación únicamente son visibles en el ámbito urbano. En el ámbito rural se tiene constancia de la romanización de algunos de los antiguos castros salamantinos como Yecla la Vieja (Yecla de Yetes) o Las Merchanas (Lumbrales), aunque la mayoría de los pequeños castros que se encuentran dispersos por la provincia aún no han sido analizados con la precisión que merecen. Algo similar ocurre con los yacimientos de época altoimperial que, por destrucción o por su posterior transformación, apenas han dejado huella en el paisaje rural salmantino. A pesar de que los yacimientos agroganaderos de esta época son muy escasos, se tiene testimonio de la existencia de otro tipo de asentamientos ligados a otras actividades económicas. En esta primera fase sería destacable el yacimiento de Las Cavenes (El Cabaco), un enclave relacionado con la explotación minera de la Sierra de Francia que se puso en funcionamiento hacia el 30-50 d. C. y que pervivió hasta finales del siglo II - principios del III. Además del aprovechamiento minero, el yacimiento presenta construcciones de almacenaje y vivienda por lo que podría considerarse uno de los primeros modelos ligados a la explotación del territorio y los recursos mineros (Ruiz del Árbol y Sánchez Palencia, 1999: 119-139; Sánchez Palencia et alii., 2000: 343-358; Ruiz del Árbol et alii., 2001).

Durante el siglo I d. C. comienzan a construirse las primeras granjas y uillae salmantinas, construcciones que, a pesar de las continuas trasformaciones estructurales y productivas, perduraron hasta época tardoantigua. En los siglos I y II las uillae del centro peninsular serían modestas construcciones que no contarían con grandes elementos ornamentales pues, su principal función sería meramente productiva. Desde finales del siglo II, los propietarios de las uillas meseteñas empezarían a introducir importantes reformas arquitectónicas, reflejadas en la cultura material arqueológica -mosaicos, estucos y mármoles- que, sin lugar a dudas, remarcarían la función residencial y recreativa de estos espacios constituyendo, además, el mejor ejemplo de explotación económica de la tierra hasta el siglo IV (Gorges, 1979; Ariño y Díaz, 1999; Chavarría, 2006: 17-35; Fernández Ochoa et alii., 2014). Por su parte, los establecimientos de menor envergadura comienzan a configurarse de forma dispersa por la mayor parte del territorio meseteño.

A partir del siglo III, las grandes uillas comienzan a coexistir en buena parte del Imperio con estos pequeños asentamientos, mayoritariamente agroganaderos, dedicados al autoabastecimiento (Molina 2015: 116-117). Estas granjas de morfología heterogénea se caracterizarían por su pequeño tamaño, su estructura funcional y por la carencia de espacios lujosos dedicados al descanso y al ocio. La falta de excavaciones arqueológicas y estudios específicos de este tipo de asentamientos rurales impide, por el momento, establecer comparativas entre las granjas salmantinas y otros establecimientos similares hallados en Lusitania (Molina 2015: 117). El estudio de las uillas salamantinas también ha sido bastante precario. En los años 80 del siglo XX la ausencia de nuevas investigaciones arqueológicas provocó que Gorges en su clásico estudio sobre las villas hispanorromanas únicamente catalogara seis uillas en el territorio correspondiente con la actual provincia salmantina (Gorges, 1979: 344-346), número que infravalora la realidad actual. A partir de esta fecha el número de asentamientos tipo uillae se ha incrementado considerablemente gracias a los datos aportados por las prospecciones, las excavaciones arqueológicas -tanto de investigación como de gestión- y sobre todo, por el exhaustivo análisis de la fotografía aérea.

\subsection{Los pavimentos musivos en la provincia de Salamanca}

Historiográficamente, las primeras noticias de pavimentos musivos en la provincia salmantina aparecen asociadas a uillas romanas y están recogidas en los 
catálogos monumentales y cartas arqueológicas de principios del siglo XX. En 1801 es descubierto el principal mosaico de la villa de San Julián de Valmuza (Doñinos), un pavimento figurativo en el que se representa iconográficamente a Pegaso y las Ninfas que fue presentado a la comunidad científica por Ceán Bermúdez en "Sumario de las Antiguedades romanas en España" en 1832 (Ceán Bermúdez, 1832). La villa fue declarada monumento del Tesoro Artístico Nacional un siglo más tarde aunque las intervenciones arqueológicas que depararon el descubrimiento de nuevos pavimentos y la reutilización de estos como parte de una necrópolis altomedieval no se realizaron hasta los años 80 del siglo XX (García y Serrano, 1996; Regueras y Pérez, 1997: 17; García Figuerola y Angoso, 1986). Esta intervención permitió confirmar la adscripción tipológica de San Julián de Valmuza a una villa de peristilo junto al que se localizó un corredor enlosado con mosaicos que daba acceso a varias estancias pavimentadas con opus signinum y opus tesselatum (Maluquer, 1956: 106-108; García y Serrano, 1996: 35-38; Regueras y Pérez, 1997: 17-19). Además de San Julián de Valmuza, en 1884 se descubren durante las tareas agrícolas, dos nuevos mosaicos geométricos en la villa de Zaratán (Campilmojado, Pino de Tormes) que son dados a conocer ese mismo año por Cesáreo Fernández Duro (Fernández Duro, 1884: 12 y Regueras y Pérez, 1997: 47-50). En 1903, Manuel Gómez Moreno en su Catálogo Monumental de España. Provincia de Salamanca, atestigua el descubrimiento por parte de D. Jacinto Vázquez de Praga de dos mosaicos geométricos de procedencia romana en Castañeda de Tormes, una pedanía de la pequeña localidad de Villagonzalo de Tormes (Gómez Moreno, 1967: 65). Dicho hallazgo también es mencionado posteriormente por Juan Maluquer en su Carta Arqueológica de España. Salamanca, quién también detalla el descubrimiento del mosaico de la villa de San Julián de Valmuza.

Con posterioridad, a principios de los años 80, fue descubierta una nueva uillae con mosaicos ubicada entre los términos municipales de Villoria y Villoruela, La Vega. En 1985 se llevó a cabo una excavación sistemática dirigida por M. García Figerola y L. Angoso en la que se descubrieron tres mosaicos geométricos, una pintura mural en la que aparecía representado un uenator y parte del complejo termal -hypocaustum y apodyterium- de la villa (García Figuerola y Angoso, 1986; Regueras y Pérez, 1997: 51-60). En las mismas fechas, se localizó en Saelices el Chico el extremo de una estancia pavimentada con mosaico y restos de un panel pintado pertenecientes a una villa del siglo IV (Regueras y Pérez, 1997: 15). Posteriormente, en los años 90, se hallaron nuevos mosaicos en la villa de Saelices el Chico, un asentamiento que presenta un complejo termal de cronología anterior y un reaprovechamiento de los espacios en época suevo-visigoda. La excavación de 1995 puso al descubierto una estructura rematada en ábside que al parecer formaba parte de un espacio ajardinado (Martín y Hernández, 1997). Un año más tarde la villa se volvió a excavar, apareciendo un nuevo mosaico y restos constructivos de una villa monumental (Pérez Olmedo et alii., 1997: 193-194). Con posterioridad, entre los años 2005-2006 se amplió la zona excavada y se localizó un pavimento musivo que representa el mito de Belerofonte y la Quimera, apareciendo Belerofonte montado sobre Pegaso y afrontando a la Quimera (Regueras y Pérez, 1997; Martín, 2007). Además de las mencionadas villas, se tiene constancia de la existencia de mosaicos de cronología romana en otros asentamientos en los que no se han llevado a cabo estudios exhaustivos: Alquería de Azán (Miranda de Azán), Barquilla (Ciudad Rodrigo), Huelmos de Cañedo (La Vellés), Los Lavaderos-Las Chivas (La Orbada), Yecla de Yeltes (Yecla de Yeltes) y Las Canteras de Santo Domino (Ciudad Rodrigo) (Fig.1). En este sentido, debemos señalar que la escasez de pavimentos musivos localizados en la provincia de Salamanca revaloriza el hallazgo del nuevo mosaico de Los Villares haciendo imprescindible un estudio de mayor envergadura del enclave que permita determinar la existencia nuevas estancias pavimentadas con opus tesselatum y constatar el estado de conservación de los mismos.

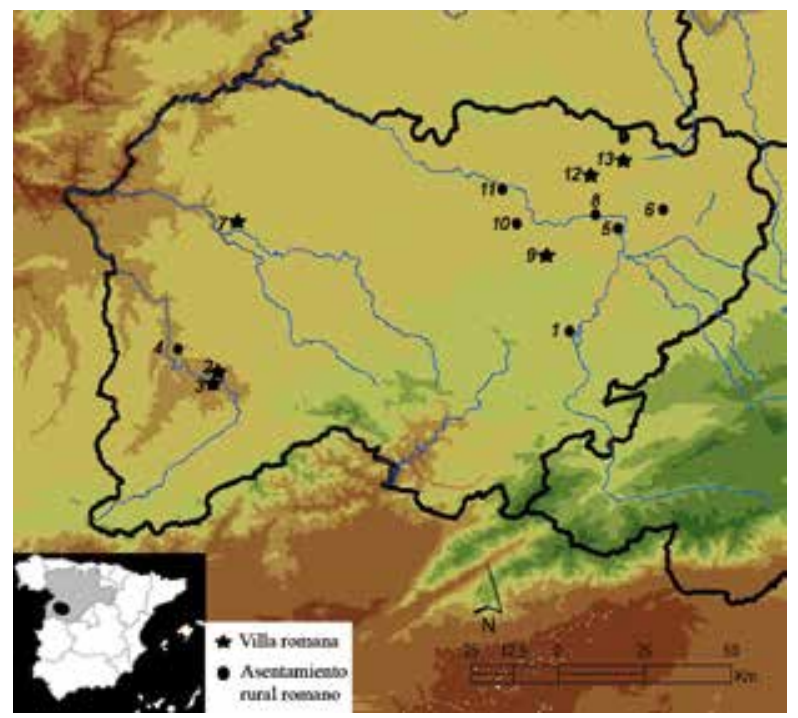

Fig. 1. Mapa de yacimientos romanos donde se han documentado mosaicos en la provincia de Salamanca (1 Los Villares; 2-3 Ciudad Rodrigo; 4 Saelices; 5 Castañeda; 6 La Vega; 7 Yecla de Yeltes; 8 San Pelayo; 9 Alquería de Azán; 10 San Julián de Valmuza; 11 Zaratán; 12 Huelmos de Cañedo; 13 Los Lavaderos-Las Chivas). / Map of Roman archaeological sites where mosaics have been documented in the province of Salamanca (1 Los Villares: 2-3 Ciudad Rodrigo; 4 Saelices: 5 Castañeda: 6 La Vega; 7 Yecla de Yeltes; 8 San Pelayo; 9 Alquería de Azán; 10 San Julián de Valmuza; 11 Zaratán; 12 Huelmos de Cañedo; 13 Los Lavaderos-Las Chivas).

\section{LOS VILLARES: UN COMPLEJO TERMAL IN- ÉDITO EN EL VALLE DEL TORMES}

\subsection{Las primeras investigaciones arqueológicas}

El antiguo yacimiento de Los Villares, catalogado a la otra orilla del regato Alhándiga y situado frente al actual asentamiento, permaneció inédito hasta 1996, año 
en el que fue prospectado e inventariado por la empresa PROEXCO S.C.L, cuyo trabajo tenía la finalidad de localizar nuevos yacimientos en diversas zonas de la provincia de Salamanca. Los Villares fue objeto de una nueva prospección de similares características en 2004 y 2005, en esta ocasión los trabajos fueron realizados por la empresa GRUPOENTORNO S.A. En estas campañas se documentó material constructivo (tegulae, ímbrices, ladrillos y losas de pizarra), cerámica a mano y a torno (principalmente cerámica común y terra sigillata) y piedras de molino que evidenciaron la ocupación romana de una zona de vega situada en la margen derecha del arroyo Alhándiga. El yacimiento quedó definido en el Inventario Arqueológico de la provincia de Salamanca como un asentamiento de tipología indeterminada que presentaba una dilatada ocupación en el tiempo desde época altoimperial hasta época visigoda. En 2015, el yacimiento fue objeto de nuevas prospecciones llevadas a cabo por el área de Arqueología de la Universidad de Salamanca, bajo la dirección de Verónica Pérez de Dios, quién documentó un gran foco de dispersión de materiales de cronología romana en la orilla izquierda del Alhándiga, lugar inédito en el que se localizaba el área principal del yacimiento. Posteriormente, la realización de varios sondeos polínicos y el descubrimiento de un fragmento de mosaico llevaron a definir el asentamiento rural como una posible uilla de grandes dimensiones cuya cronología abarcaría el periodo romano bajoimperial y visigodo. Actualmente, la dispersión de materiales del yacimiento se extiende por ambas márgenes del arroyo Alhándiga, presentando el mayor foco de concentración de materiales en el área catalogada en el año 2015, zona en la que estarían emplazadas las estructuras habitacionales y productivas.

\subsection{La campaña de 2015: descubrimiento de un nuevo complejo termal}

En otoño de 2015 se inició una nueva campaña de excavaciones arqueológicas de urgencia en el yacimiento que permitió sacar a la luz parte del complejo termal de un asentamiento rural romano de grandes dimensiones cuya ocupación quedaría constatada gracias al material cerámico desde el siglo III al siglo V-VI aunque, posiblemente, exista una fase de ocupación anterior que, por el momento, no se ha podido determinar. Antes de llevar a cabo la intervención se procedió a la limpieza del área cultivada y a la realización de una prospección previa para recoger el material arqueológico en superficie. Posteriormente, se planteó un área de excavación limitada por una cuadrícula de $12 \mathrm{~m}$. de longitud por $9 \mathrm{~m}$. de anchura (108 $\left.\mathrm{m}^{2}\right)$ que, a su vez, fue subdividida en cuadrículas menores de $4 \mathrm{~m}$. por 3 m., trabajando de este modo sobre nueve cuadrantes. Teniendo en cuenta los objetivos de nuestra investigación, se decidió ampliar el área de investigación y abrir una pequeña cata en una zona adyacente a la del sondeo principal. Por ello se procedió a la realización de dos pequeños sondeos de $10 \mathrm{~m}$. de largo por $1 \mathrm{~m}$. de ancho que se cruzaban entre sí, situándose este cruciforme a unos $40 \mathrm{~m}$. de la zona de excavación. Con ambas actuaciones se pretendía conocer el desarrollo de la secuencia estratigráfica de amortización de las estructuras, comprobar la extensión y el grado de conservación de los restos constructivos del yacimiento que permitieran reconocer la parte del enclave que estábamos excavando y hallar nuevos materiales cerámicos que pudieran ofrecer una cronología concreta del abandono. Una vez finalizada la excavación y la toma de datos correspondiente, las estructuras documentadas fueron cubiertas con geotextil y posteriormente tapadas con tierra, devolviéndose el área al estado previo a la intervención arqueológica.

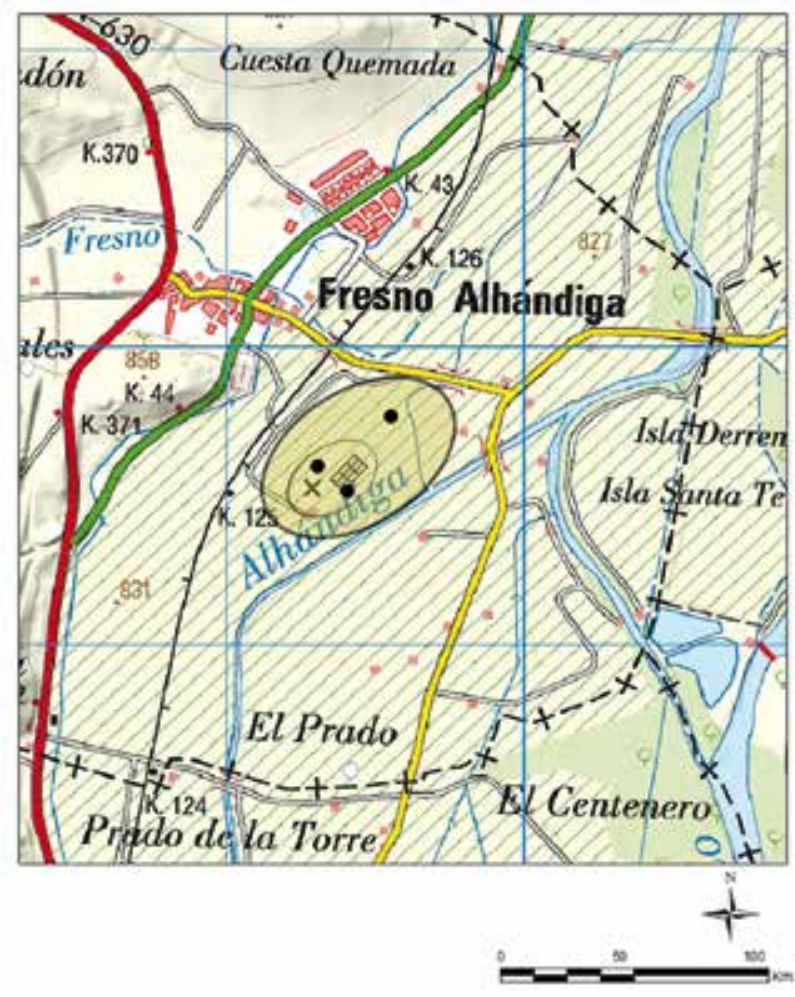

Fig.2. Mapa del yacimiento de Los Villares (Fresno Alhándiga) con excavación, catas polínicas y la dispersión geográfica de materiales arqueológicos. / Map of the site of Los Villares (Fresno Alhándiga) with the archaeological dig, palynological samples and the geographical dispersion of the archaeological material.

\section{Sondeo principal}

Aunque el enclave posee una escasa potencia arqueológica, la excavación permitió documentar la existencia de tres estancias bien conservadas: una pavimentada con un mosaico geométrico con representaciones zoomorfas y dos con opus signinum e identificar varios niveles estratigráficos que han permitido corroborar la fase de ocupación romana. A escasos 20-30 cm de profundidad, se documentó buena parte de los pavimentos de tres estancias y varias zonas que presentaban pequeños derrumbes de materiales cons- 
tructivos (tegulae e imbrices). En los sectores 6, 7 y 8 , bajo una de las áreas de derrumbe, apareció un pavimento de opus signinum bastante degradado que presentaba hundimientos lineales por encontrarse sobre un hypocaustum que conservaba los arcos y columnas que conformaban las cámaras de aire caliente del caldarium de las termas. La localización del hypocaustum nos permitió identificar las estancias halladas durante la excavación en el sondeo principal. De este modo, la sala pavimentada con opus signinum en la que se encontró un pequeño pozo circular ha sido identificada como el frigidarium y la estancia pavimentada con mosaico habría tenido la función de tepidarium (Fig. 3). Frecuentemente, el tema del que se componen los mosaicos suele marcar el uso del propio espacio, proporcionando la elección de un determinado motivo un mensaje implícito sobre el uso de una determinada habitación o sus funciones (Dunbabin, 2002: 304). En este caso, debido a que la excavación ha sido parcial no se puede restituir el esquema de circulación de las termas, pero al haberse localizado una sala afectada por el sistema de hypocaustum puede suponerse que nos encontramos en la zona templada de las mismas.
El frigidarium es una estancia rectangular pavimentada con opus signinum que, aunque no está completa, presenta pequeñas dimensiones, unos $10 \mathrm{~m}^{2}$. La sala, delimitada por un muro de $60 \mathrm{~cm}$. de grosor realizado con piedras de medio tamaño, estaba comunicada con el caldarium por una puerta de acceso que conservaba un pequeño arranque de los muros de unos 3-5 cm. En esta habitación, es destacable la presencia de un pequeño agujero circular de 47 por $50 \mathrm{~cm}$. de diámetro que, posiblemente, sería utilizado para concentrar el agua en los momentos de limpieza del suelo.

El pavimento musivo aparecido en el centro del sondeo principal, delimitado al NO y al NE por dos lienzos de muro prácticamente desaparecidos, conforma el suelo del tepidarium. La sala presenta un acceso al ambiente frío, quedando únicamente sin determinar el cierre de esta por los lados $\mathrm{E}$ y W pues, parte de las estancias del asentamiento se han perdido por las labores agrícolas o están prácticamente desaparecidas. El mosaico geométrico con representaciones figuradas de peces y delfines presenta unas medidas de $17 \mathrm{~m}^{2}$, aunque no se conserva en su totalidad pues el desnivel del terreno y las labores agrícolas han motivado

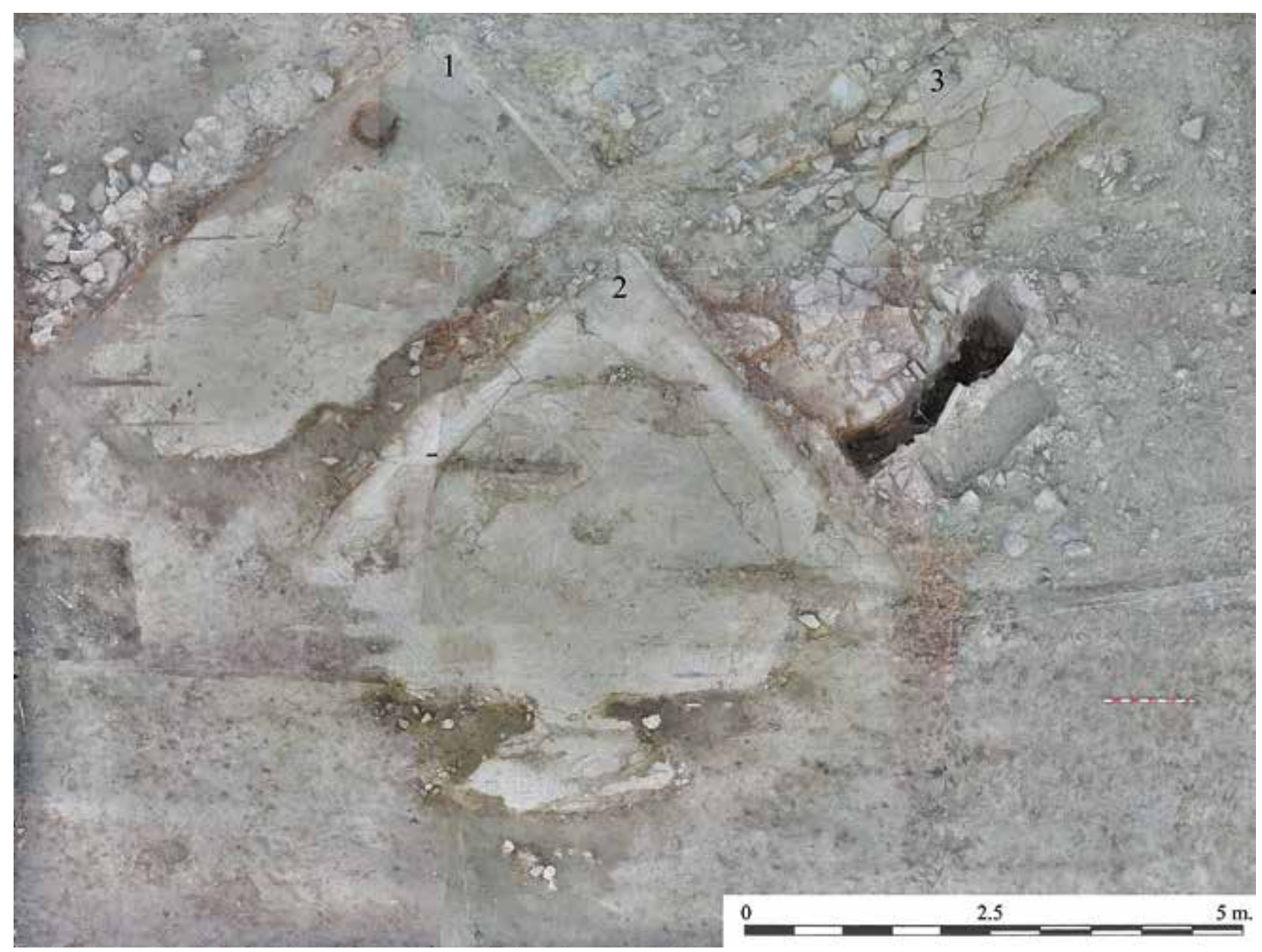

Fig. 3. Fotografía de las estancias de la excavación: (1) Frigidarium (opus signinum); (2) tepidarium (pavimento musivo) y (3) caldarium con derrumbes. $/$ Photograph of the stays of the excavation: (1) Frigidarium (opus signinum); (2) tepidarium (mosaic floor) and (3) caldarium with landslides. 
la pérdida irreparable por la parte sur del mismo. La coloración del pavimento no ha podido ser apreciada en todo su esplendor debido a las concreciones calcáreas, pese a ello ha sido posible identificar teselas de cinco tonalidades diferentes: blanco, azul oscuro, azul claro, rojo oscuro y rojo claro.

El mosaico está enmarcado por un cuadrado de nudos salomónicos de $11,5 \mathrm{~cm}$. de ancho, un motivo ornamental importado de Oriente en época de Trajano que ha sido utilizado frecuentemente en los motivos de los pavimentos de yacimientos hispanorromanos (Blázquez Martínez et alii, 1993). En los ángulos del cuadra- do son visibles tres cráteras gallonadas ${ }^{1}$, de las que salen hojas de hiedra que completan la enmarcación del primer cuadrado con la segunda enmarcación de nudos salomónicos que presenta forma circular (Fig.4D). La crátera es un motivo frecuente representado en los mosaicos romanos, de hecho, los ejemplos de pavimentos musivos peninsulares en los que aparecen representados jarrones o cantharus, son abundantes en yacimientos con cronología tardorromana/paleocristiana (Fernández Ochoa, 1982: 368). En Castilla y León son numerosos los yacimientos en los que se han encontrado decoraciones de este tipo, siendo los más
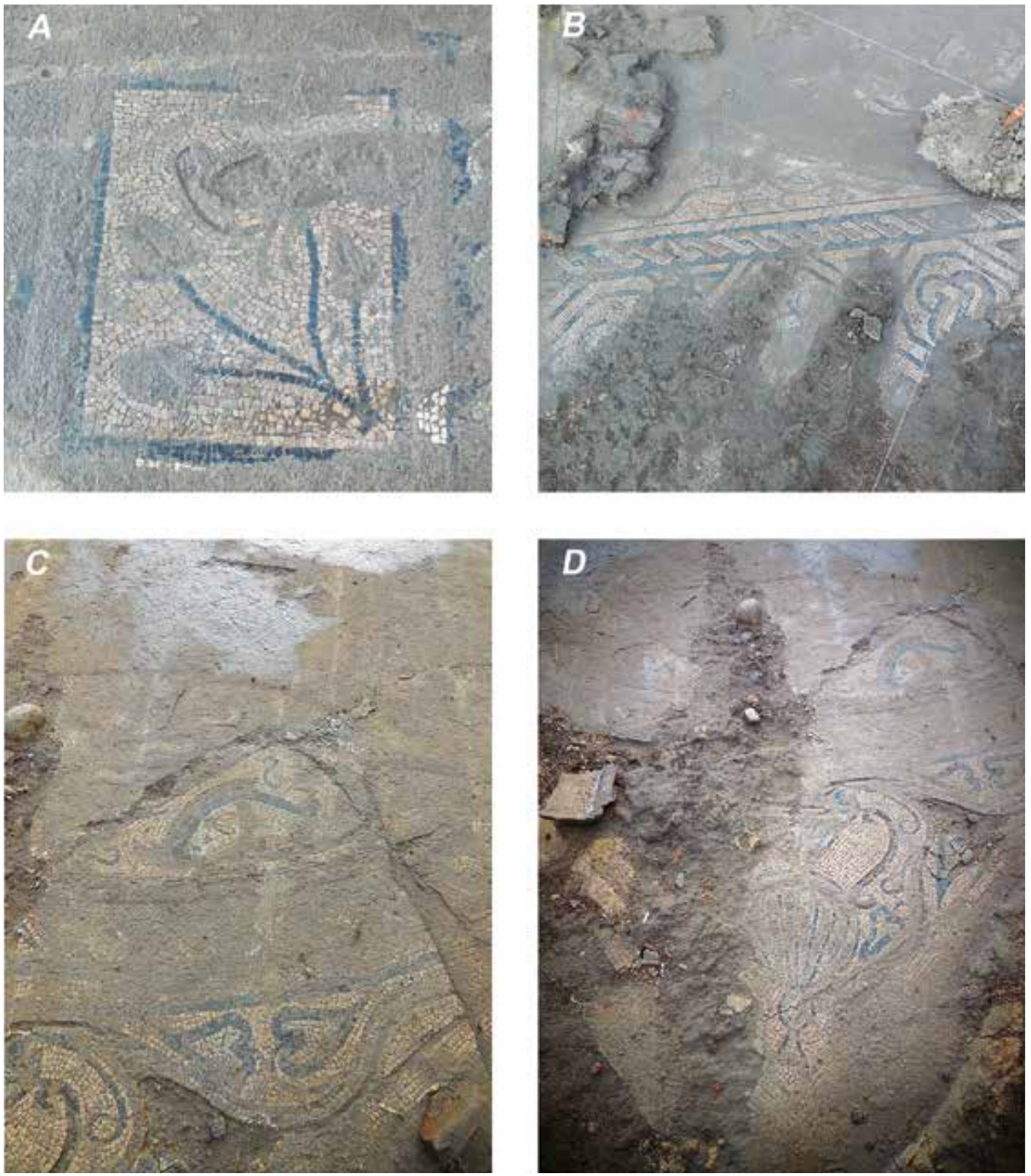

Fig. 4. Detalles del mosaico del tepidarium: motivo vegetal (A); nudos salomónicos $(B)$, delfín (C) y crátera (D). / Tepidarim's mosaic details: vegetal motif $(A)$; Solomonic knots (B), dolphin (C) and vase (D)

1 La cuarta crátera posiblemente ha desparecido. 
relevantes el famoso mosaico de la crátera de la villa de Almenara-Puras (Neira y Mañanes, 1998: 24); los pavimentos de la villa del Prado, también situada en Valladolid, donde la crátera es uno de los motivos más empleados ya que llegan a sumar hasta 16 (Neira y Mañanes, 1998: 60); el mosaico de la casa número 3 de Uxama (Soria) con cráteras sobre trípodes que también tienen un paralelo exacto en una casa romana de León (Fernández Galiano, 1980:22) o el pavimento la casa $n^{\circ}$ 3 de Clunia (Burgos) donde se encontró el denominado "mosaico de las cráteras". Se trata de cráteras doradas de cuerpo hemisférico con asas dobles, pie con botón y base triangular colocadas en las enjutas mayores (López Monteagudo, Navarro y de Palol, 1998: 68).

Tras la enmarcación circular de nudos salomónicos la composición presenta en el centro del mosaico un elemento octogonal de $85 \mathrm{~cm}$. en el que se distingue un soliforme de ocho pétalos realizados a base de teselas de coloración rojo oscuro que, posiblemente, fuera el emblema central del pavimento musivo. El motivo central aparece rodeado por ocho cuadrados de unos $40 \mathrm{~cm}$. de lado, enmarcados por nudos salomónicos polícromos, en cuyo interior son distinguibles hojas y flores realizadas a base de teselas azules y rojas sobre un fondo de teselas blancas (Fig.4- A y B). En la parte intermedia de estos cuadrados, es posible apreciar la formación de ocho triángulos enmarcados también por nudos salomónicos que, al igual que estos, se decoran interiormente. En el espacio intermedio exterior, localizado entre los cuadrados y el nudo salomónico circular se han hallado ocho espacios triangulares en los que es posible identificar cuatro motivos pisciformes y cuatro delfines (Fig.4- C). Los delfines son un tema recurrente en la musivaria de la zona levantina y andaluza, no así en la castellanoleonesa. La factura con la que fueron hechos no resulta muy cuidada, pero son similares a los delfines hallados en la villa de los Vergeles (Granada) (Marín, 2011: 181). En la parte más deteriorada del mosaico únicamente es posible distinguir varios octógonos en los que aparece representado un nudo de Salomón tangente (Fig.5).

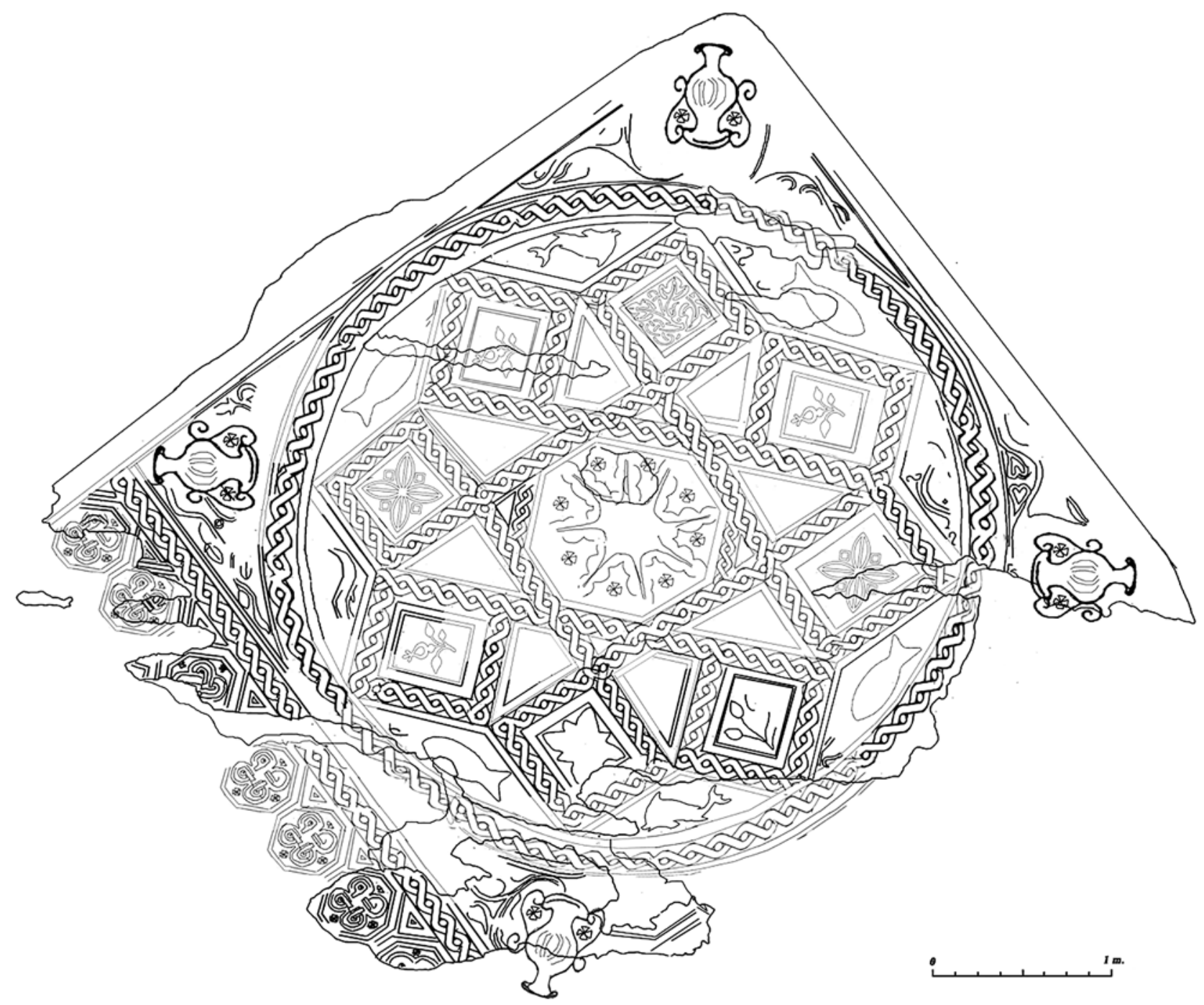

Fig. 5. Reconstrucción idealizada del mosaico romano. / Idealized reconstruction of Roman mosaic. 
Por debajo del opus tesselatum fue posible documentar los dos niveles de preparado: el primer nivel o nucleus, de unos 5-7 cm. de potencia está compuesto por mortero de cal sobre el que se colocarían cada una de las teselas que componen el mosaico geométrico con representaciones zoomorfas. Bajo el nucleus se encontró el rudus, una capa de unos $10 \mathrm{~cm}$. de potencia compuesta por piedras de río de pequeño tamaño unidas entre sí por medio de mortero de cal que estaba directamente depositada sobre el terreno natural.

Junto al tepidarium estaba situada el caldarium, una estancia pavimentada con opus signinum que presentaba peores condiciones de conservación que las salas anteriormente descritas, a pesar de estar localizada a una mayor profundidad del nivel de arada y ubicarse bajo un nivel de derrumbe de materiales constructivos de $5-10 \mathrm{~cm}$. de potencia. Se trata de una estancia parcialmente hundida con una superficie estimada de $22 \mathrm{~m}^{2}$, bajo la cual se halló un hypocasutum que conserva las suspensurae en arco, morfología característica de los hypocaustum de Lusitania en los que prima la utilización de arcos y no de las tradicionales pilae (Reis, 2004:55). Los arcos realizados en ladrillo y apoyados sobre pilae, del mismo material miden 90 $\mathrm{cm}$., presentando un vano interior de $60 \mathrm{~cm}$. La separación entre arcadas es de $50 \mathrm{~cm}$., por lo que ha sido posible corroborar la existencia de, al menos, 6 hiladas de arcos que conforman el hypocaustum del caldarium (Fig.6). Junto a este, se localizaría el praefurnium, ubicado junto al sector 7 del sondeo principal que estaría comunicado con el hypocaustum por un canal de calor que permitiría caldear la estancia.

La excavación de este hypocaustum permitió documentar el abandono del yacimiento. En dicho relleno se documentó un nivel de derrumbe de $40 \mathrm{~cm}$. de potencia en el que se encontraron abundantes restos de material constructivo. Tras este estrato se confirmó la existencia de dos niveles estériles: uno de coloración blanquecina y otro anaranjado y muy granuloso que tenía una potencia de apenas $10 \mathrm{~cm}$. Este último nivel cubría un estrato arcilloso marrón de unos $28-30 \mathrm{~cm}$. de potencia en el que se recuperaron abundantes restos de fauna y material cerámico. La escasez de espacio en la parte media-baja de las arcadas impidió continuar la excavación del último estrato empedrado pues, era preciso desmontar parte de la estructura del hypocaustum.

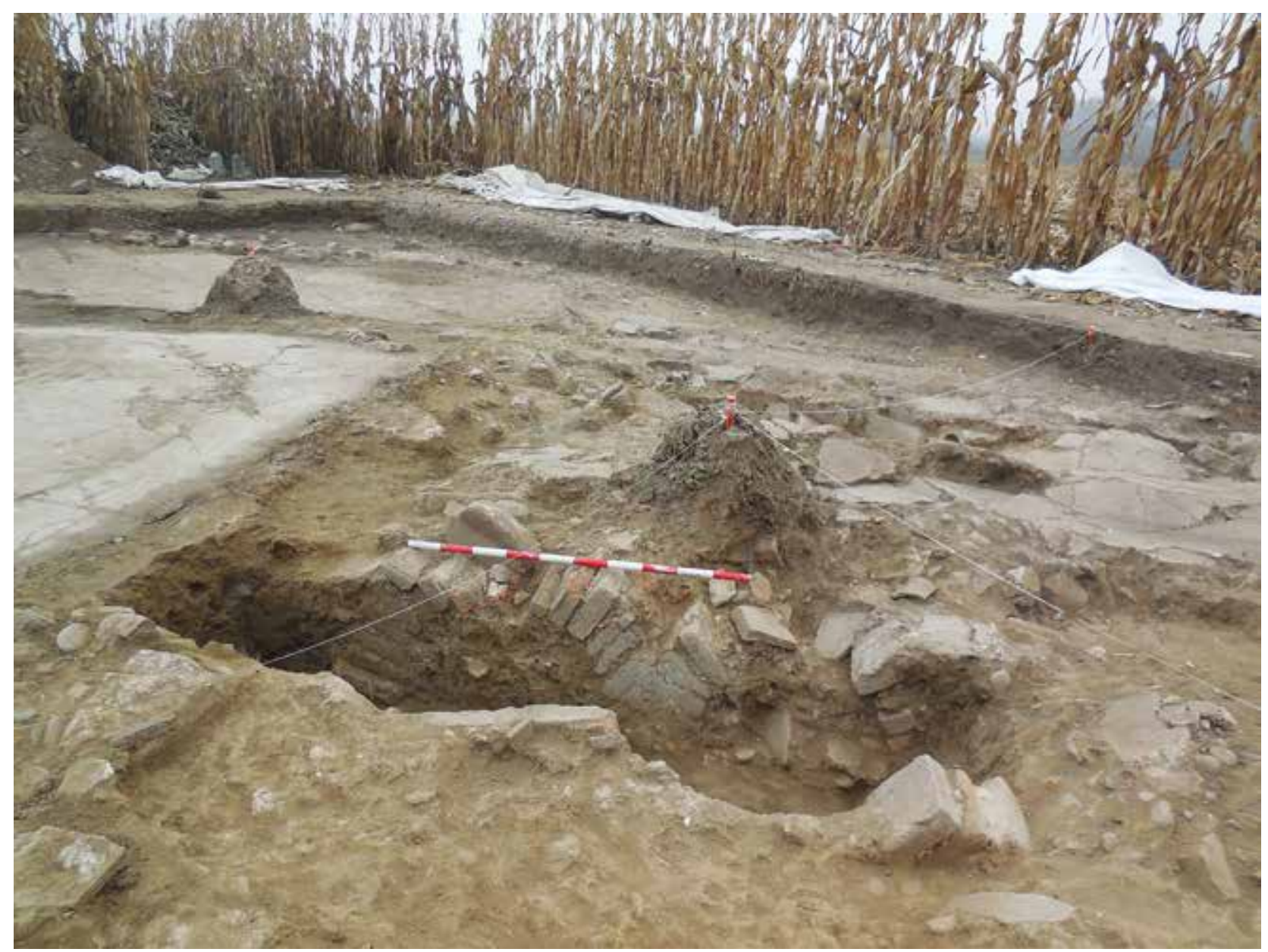

Fig. 6. Vista frontal de los arcos del hypocaustum del caldarium. / Front view of the arches of hypocaustum of caldarium. 
En lo que respecta a la decoración pictórica, destacar la localización de pequeños fragmentos de estuco de diversos colores (rojo, amarillo, blanco y negro), pertenecientes a la parte baja del zócalo, que revestirían las paredes de las estancias tepidarium y caldarium. La escasez de restos de pintura mural ha impedido constatar la tipología de elementos ornamentales y decorativos existentes en las estancias de Los Villares. Pese a ello, el rico cromatismo y la carencia de elementos animales, vegetales o paisajísticos hace pensar en la imitación de la decoración marmórea de las estancias. Junto a los restos pictóricos, en el sondeo principal se recuperaron 1018 fragmentos cerámicos $(85,1 \%$ del total de fragmentos recuperados en la excavación arqueológica) que permiten encuadrar la secuencia de abandono del yacimiento entre los siglos IV-V d.C. Todos ellos fueron analizados conjuntamente por pertenecer a la fase de colmatación del asentamiento.

El gráfico refleja la primacía de los fragmentos de cerámica común (CCC, CC, CC engobadas y dolias) en los que se engloba una gran variedad de tipologías cerámicas con pastas y coloraciones diferentes sobre los fragmentos cerámicos finos adscritos a las familias de cerámica de paredes finas, cerámica pintada y las diversas variedades de terra sigillata. El grupo de sigiIlatae es muy abundante (32,1\% del total de fragmentos cerámicos del sondeo principal) aunque, debido a su estado fragmentario las formas reconstruidas han sido muy escasas, siendo las más destacadas las Drag.24/25 (2016/1/1; 2016//245); Drag. 37 t (2016/1/260; 2016/1/339); Ritt. 8 (2016/1/809) y Lam. 42 (2016/1/8; 2016/1/139; 2016/1/264; 2016/1/407; 2016/1/914). Así mismo, es destacable la alta presencia de fragmentos de terra sigillata africana (3,5\% del total de la cerámica del sondeo principal) que podría haber llegado al emplazamiento a través del comercio por la vía de la Plata.

\section{Segundo sondeo}

Como complemento a la excavación realizada para documentar el estado de conservación y extensión del mosaico hallado en los sondeos polínicos se realizó otra cata situada a $40 \mathrm{~m}$. de distancia del sondeo principal. El propósito de esta última era comprobar la extensión del yacimiento y, en el caso de que se documentaran nuevas estructuras, conocer la profundidad a la que se localizan.

Con el fin de ratificar los objetivos, se decidió realizar dos catas de $10 \mathrm{~m}$. de largo por $1 \mathrm{~m}$. de ancho que se cruzaban entre sí y que serían rebajadas $30 \mathrm{~cm}$. para equiparase al nivel en el que se habían encontrado el resto de estructuras de la villa. Los escasos materiales cerámicos y constructivos localizados a esta profundidad, hacían pensar en la destrucción de las estancias del lado NE del asentamiento por ello, se decidió continuar excavando el área central de este sondeo en el que se cruzaban ambas catas. A $40 \mathrm{~cm}$. de profundidad se halló una estructura muraria cuadrangular que se extendía hacia el este-oeste y estaba cerrada al norte. Se trata de una estructura de piedra de mediano tamaño, de unos $70 \mathrm{~cm}$. de ancho, que está formada por varias hiladas. Asociada a ella, aparecieron restos de carbón y numerosos fragmentos de cerámica común de cocina con marcas de exposición al fuego que, podrían indicar la pertenencia de la otra estructura posiblemente dedicada a la producción agrícola.

\section{RESULTADOS Y CONCLUSIONES}

A partir del siglo III d.C se produce un cambio en las estructuras de poblamiento rural romano, siendo las opulentas uillae el ejemplo más destacado y extendido por todo el territorio peninsular (Chavarria, 2005: 518-

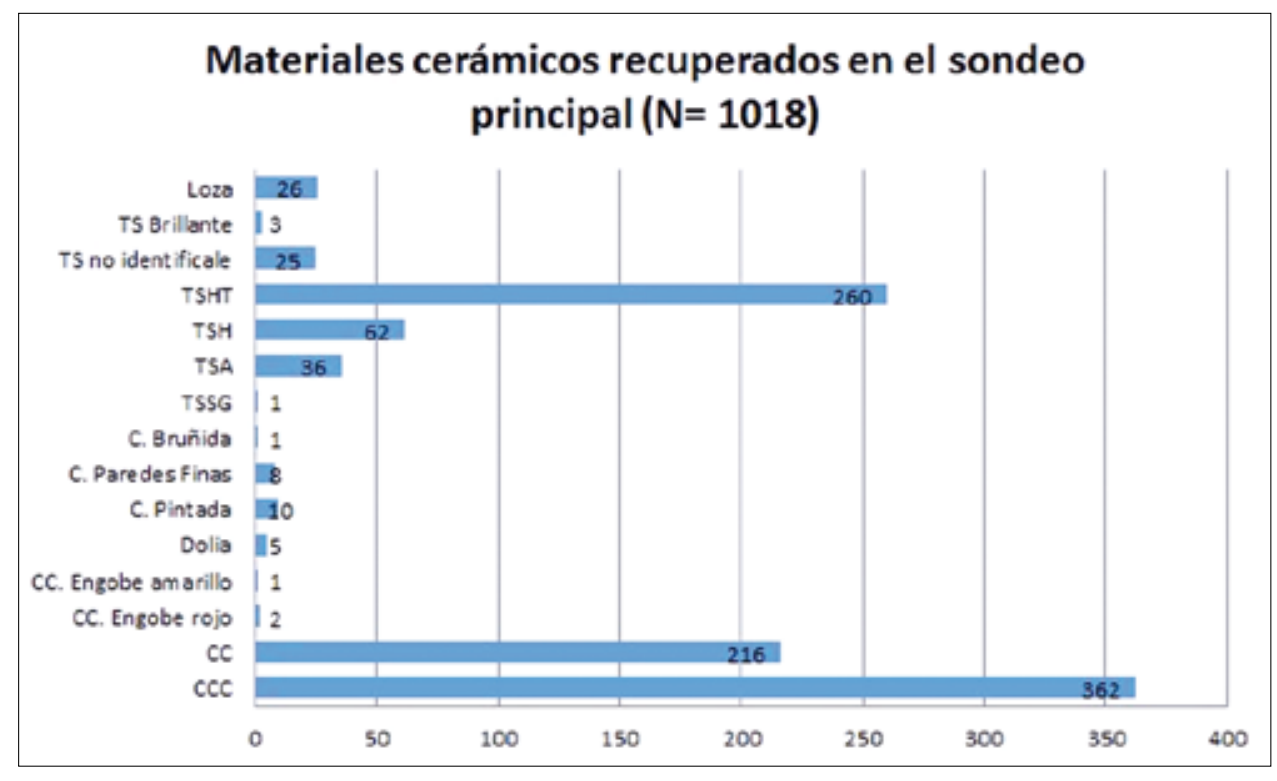

Fig. 7. Materiales cerámicos recuperados en el sondeo principal de la excavación arqueológica de Los Villares. Campaña 2015. / Ceramic materials recovered in the main hole of the archaeological excavation of Los Villares. Campaign 2015. 
555 y Fernández Ochoa et alii., 2008). Los trabajos de prospección y excavación arqueológica desarrollados en el inédito asentamiento romano de Los Villares, han permitido delimitar parte de las estancias termales y precisar el abandono del mismo. Los restos identificados corresponden a un conjunto de estructuras que podrían estar relacionados con los baños del asentamiento aunque, por el momento, no ha sido posible recuperar todas las estancias que confirmarían dicha hipótesis. Los complejos termales rurales no son exclusivos de las villas, sino que pueden aparecer también asociados a las mansiones viarias, ya que era necesaria una zona de baño para el aseo y descanso de los viajeros (Corsi, 2000: 251). Según Fernández Castro, las estancias termales se localizarían en el sector noroccidental de los grandes asentamientos romanos factor que, debido a la falta de excavaciones posteriores, no ha podido ser corroborado en el yacimiento analizado (Fernández Castro, 1982: 102). A pesar de ello, junto a la zona residencial es frecuente la aparición de otro tipo de estructuras ligadas a las funciones productivas del asentamiento (almacenes, establos...), que en el caso de Los Villares, podrían situarse al NE del complejo termal.

Aunque no es posible adscribir el yacimiento a una tipología concreta de poblamiento rural romano, la ingente dispersión de materiales arqueológicos localizados en prospección, la cercanía a la vía de la Plata y el desconocimiento de la localización de la mansio Sentice ubicada por Roldán en una zona en la que actualmente no existe ningún tipo de yacimiento arqueológico hace pensar que podríamos estar ante un complejo termal que formaría parte de un asentamiento de mayores dimensiones que podría corresponderse con dicha mansio. La privilegiada ubicación del asentamiento en zona de paso continúo de mercancías y personas, la cercanía de este a una corriente de agua permanente -Tormes y Alhándiga $\neg-$, el fácil aprovisionamiento de los recursos primarios de la zona y la cercanía de otros asentamientos tipo villae y granja que podría proveer de recursos a la mansio, son otros factores que, coincidirían con las hipótesis que Corsi planteó para identificar los asentamientos tipo mansio (Corsi, 2000: 245).

Las estructuras documentadas parecen sugerir que el yacimiento tardío podría tener una cronología anterior a la documentada aunque, la ausencia de nuevas intervenciones arqueológicas ha impedido confirmar esta hipótesis. Por el momento, lo único que se ha podido documentar a través de la prospección arqueológica es una dispersión de material cerámico y constructivo de unas 20 ha. que es visible en las tierras de cultivo situadas en la otra orilla del arroyo Alhándiga. Precisamente, la gran extensión de un asentamiento que superaba con creces el tamaño medio de las villas romanas tormesinas planteó la hipótesis de estar ante un yacimiento que por sus dimensiones y su cercanía a la Vía de la Plata podría identificarse con una mansio. Aunque no ha sido posible reconstruir el trazado completo del famoso camino romano, las evidencias en las fuentes antiguas nos ofrecen pistas sobre la ubicación de estas estaciones de carretera. Arqueológicamente, la realización de algunas intervenciones ligadas a la construcción de la actual autovía de la Plata y el uso de la fotografía aérea han permitido reconocer ciertos trazados del Iter ad Emeria Asturacicam en territorio extremeño (Gorges, Cerrillo y Nogales, 2004 y Sarasola et alii, 2006) y salamantino, siendo los más destacados en la provincia charra el tramo del Puerto de Béjar (Gómez Moreno, 1967: 54-57; Pérez, 2007: 33-42 y Figuerola y Menéndez 2007: 43-72) y el de la entrada a la ciudad de Salamanca por el Prado del Zurguén (Salvador y Viñé, 2007: 73-80). Por su parte, la ubicación de las mansiones ubicadas en la actual provincia de Salamanca-Caelionicco (m.p. XXII), Ad Lippos (m.p. XII), Sentice (m.p. XV) y Salmantice (m.p. XXIIII) - es conocida a través Itinerario Antonio, el Anónimo de Rávena y las tablas de barro de Astorga. Concretamente, la ubicación de la mansio Sentice ha ido modificándose sustancialmente. Según el Itinerarium Antonini Augusti se localizaría en la milla 149 de la vía de la Plata; el padre César Morán y Blázquez la situaron en Navarredonda de Salvatierra (Morán, 1946: 82; Blázquez, 1912) y, posteriormente, Roldán la emplazó en la finca de La Dueña de Abajo (Pedrosillo de los Aires) lugar en el que hasta el momento se cree que se localizaba (Roldán, 1971, 1998: 316). La abundante dispersión de restos materiales en los campos colindantes al núcleo central del asentamiento estudiado hace pensar que, posiblemente, estamos ante un yacimiento rural de tipología indeterminada que presenta mayor envergadura que los establecimientos agroganaderos tipo uilla del entorno del río Tormes. En este sentido, la entidad de los nuevos restos arqueológicos hallados junto a la Vía de la Plata y la carencia de materiales arqueológicos en las cercanas ubicaciones propuestas para la mansio por los autores anteriormente citados deja abierta la posibilidad de encontrarnos ante la Sentice citada por las fuentes.

Aunque los resultados alcanzados han superado las expectativas iniciales somos conscientes de la parcialidad de unos datos obtenidos de una excavación de pequeñas dimensiones $(9 \times 12$ m.) y de una prospección intensiva que nos permite dilucidar ciertas conclusiones. En primer lugar, señalar que todos los materiales recuperados corresponden a momentos de ocupación tardía (ss. IV-V), es decir, que podrían estar ligados a la época de abandono del asentamiento. A pesar de la caída del Imperio Romano, las fuentes evidencian ciertas correrías de los bárbaros en la mitad occidental de la Península Ibérica al menos durante el siglo V, por lo que las infraestructuras de comunicación romana, aún bien conservadas, continuarían siendo utilizadas. En este sentido, el arreglo del puente y la muralla de Mérida en época visigoda, refutaría la idea de que la red viaria continuaría en uso en el siglo V (Crogiez-Pétrequin, 2014: 307-317 y Arce, 2008: 121-126). En base a los resultados obtenidos en los sondeos realizados en 2015, no es posible precisar una datación fundacional fiable del emplazamiento pues, el sondeo 
realizado en el sector 3 , bajo los niveles habitacionales, ha proporcionado escasos materiales arqueológicos que parecen adscribirse a época tardía. Por el momento, el único dato verificado y fechable arqueológicamente es la construcción de unas termas entre los siglos III y IV. Datable en esta época es también el pavimento musivo correspondiente a caldarium de las termas pues, la combinación de sus esquemas geométricos y vegetales y las dimensiones de nucleus lo vinculan a época tardía. Asimismo, señalar que con el fin de proteger las estructuras aparecidas en la intervención arqueológica, se decidió cubrir las zonas intervenidas como mejor fórmula para su salvaguarda, evitando así futuros deterioros. Por todo ello, se estima prioritario la realización de nuevas intervenciones arqueológicas en las que un equipo de la Universidad de Salamanca ya está trabajando que, permitan comprender la estructura del asentamiento y que a su vez, complementen la información sobre el poblamiento rural romano en la provincia de Salamanca.

\section{BIBLIOGRAFIA}

Alonso, O.A., Ariño, E., 2001. Informe técnico: Trabajos de Documentación Arqueológica en el yacimiento de San Pelayo (Aldealengua, Salamanca). Salamanca: Informe inédito. Biblioteca del Museo de Salamanca.

Arce, J., 2008. La inscripción del puente de Mérida de época del rey Eurico (483 d.C.). Pyrenae, 39(2), 121-126.

Ariño, E., 2006. Modelos de poblamiento rural en la provincia de Salamanca (España) entre la Antigüedad y la Alta Edad Media. Zephyrus 59, 317-337.

Ariño, E., Dahí, S., García-García, E., Liz, J., Rodríguez, J., Sala, R., de Soto, M.R., Tamba, R., 2015. Intensive survey in the territory of Salamanca: Aerial photography, geophysical prospecting and archaeological sampling. Journal of Roman Archaeology 28(1), 283-301.

Ariño, E., Barbero, L., Díaz, P.C., 2004-2005. El yacimiento agrícola de El Cuquero y el modelo de poblamiento en época visigoda en el valle del río Alagón (Salamanca, España). Lancia 6, 205-231.

Ariño, E., Díaz, P.C., 1999. La economía agraria de Hispania romana: colonización y territorio. Studia Historica. Historia Antigua 17, 153-192.

Ariño, E., Riera i Mora, S., Rodríguez, J., 2002. De Roma al Medievo. Estructuras de hábitat y evolución del paisaje vegetal en el territorio de Salamanca. Zephyrus 55, 283-309.

Ariño, E., Rodríguez, J., 1997. El poblamiento romano y visigodo en el territorio de Salamanca. Datos de una prospección intensiva. Zephyrus 50, 225-245.

Ariño, E., de Soto García, M.R., 2016. Técnicas de muestreo en la prospección arqueológica: la experiencia del ager Salmanticensis. Anales de Arqueología Cordobesa 27, 35-58.

Blanco González, A., López Sáez, J.A., 2013. Dynamics of pioneer colonisation in the Early Iron Age in the Duero basin (Central Iberia, Spain): Integrating archaeological and palynological records. Environmental Archaeology 18(2), 102-113.

Blanco González, A., López Sáez, J.A., López Merino, L., 2009. Ocupación y uso del territorio en el sector centromeridional de la cuenca del Duero entre la Antigüedad y la alta Edad Media (siglos I-IX d. C.). Archivo Español de Arqueología 82, 275-300.

Blázquez, A., 1912. Vía romana de Mérida a Salamanca. Boletín de la Real Academia de la Historia LXI, 101-116.
Blázquez Martínez, J.M., López Monteagudo, G., Neira Jiménez, M.L., San Nicolás Pedraz, M.P., 1993. Hallazgos de los mosaicos romanos en Hispania (1977-1987). Espacio, Tiempo y Forma. Serie II, Historia Antigua 6, 221-296.

Ceán, J.A., 1832. Sumario de las Antigüedades Romanas que hay en España. Madrid.

Chavarría, A., 2005. Villas in Hispania during the fourth and fifth centuries. In: Bowes, K., Kulikowski, M. (Ed.), Hispania in Late Antiquity, 518-552. Brill, Leiden. Current Perspectives.

Chavarría, A., 2006. Villas en Hispania durante la Antigüedad tardía. In: Chavarría, A, Arce, J., Brogiolo, G.P. (eds.), Villas tardoantiguas en el Mediterráneo Occidental, 17-35. Anejos de Archivo Español de Arqueología.

Corsi, C., 2000. Stazioni stradali e cursus publicus. Note di tipología dell'insediamento lungo la viabilità romana. Orizzonti. Ressegna di archeologia I, 243-253.

Crogiez-Pétrequin, S., 2014. La statio, les stationarii et le cursus publicus dans le Code justinien. In: France, J., Nelis-Clément, J. (Ed.), La statio. Archéologie d'un lieu de pouvoir dans l'empire romain, 307-317. Bourdeaux.

Dahí Elena, S., 2007. Un contexto cerámico de la Antigüedad tardía: el yacimiento de San Pelayo (Aldealengua, Salamanca). Nuevos datos sobre la cronología de las pizarras visigodas. Pyrenae 38, 79-104.

Dunbabin, K.M., 2002. Mosaics of the Greek and Roman world. Cambridge.

EXCAR, 1991-1992. Prospecciones arqueológica en ocho términos municipales de la provincia de Salamanca: Aldealengua, Aldearrubia, Cabeza de Framontanos, Fuenterroble de Salvatierra, Huerta, San Morales, Valsalabroso y Villar de Peralonso. Informe inédito. Biblioteca del Museo de Salamanca.

Fanjul, A., Menéndez, L.R., Álvarez, A., 2005. La fortaleza de Alesga (Teverga, Asturias): Una posible Turris de control altoimperial. Gallaecia 24, 181-191.

Fernández Castro, M.C., 1982. Villas romanas en España. Madrid. Fernández Duro, C., 1884. Descubrimiento de Antigüedades en Salamanca. BRAH 5, 12

Fernández Galiano, D., 1980. Mosaicos hispánicos de esquema a compás. Guadalajara.

Fernández Ochoa, C., 1982. Asturias en la época romana. Madrid.

Fernández Ochoa, C., Salido Domínguez, J., Zarzalejos Prieto, M., 2014. Las formas de ocupación rural en Hispania. Entre la terminología y la praxis arqueológica. CuPAUAM 40, 11-136.

Fernández Ochoa, C., García Enteno, V., Gil Sendino, F. (Dir.), 2008. Las "villae" tardorromanas en el Öccidente del Imperio. Arquitectura y función. In: IV Coloquio Internacional de Arqueología en Gijón, 215-238. Gijón.

Fornell Muñoz, A., 2005. Las villae romanas en la Andalucía mediterránea y del Estrecho. Universidad de Jaén.

France, J., Nelis-Clément, J., 2014. La statio. Archéologie d'un lieu de pouvoir dans l'empire romain. In: France, J., Nelis-Clément, J. (Ed.), La statio. Archéologie d'un lieu de pouvoir dans l'empire romain, 11-15. Bordeaux.

Garcia Figuerola, M., 1989. Prospección de villas romanas en Salamanca. Informe inédito en la biblioteca del Museo de Salamanca.

García Figuerola, M., Angoso, L., 1986. Informe de la excavación de la villa romana de "La Vega" (Villoria-Villoruela, Salamanca). Informe inédito. Biblioteca del Museo de Salamanca, Salamanca.

García Figuerola, M., Menéndez Bueyes, L.R., 2007. La Vía de la Plata a su paso por la Sierra de Béjar. El tramo Casa Adriano-Puente de la Malena (Salamanca). In: Gillani, G., Santonja, M. (coord.), Arqueología en la Vía de la Plata (Salamanca), 4372. Béjar (Salamanca). 
García Morales, M., Serrano Piedecasas, L., 1996. La villa romana de San Julián de la Valmuza. Excavaciones de 1984 y 1985. Fondos del Museo de Salamanca, Madrid.

Gómez Moreno, M., 1967. Catálogo monumental de España: Provincia de Salamanca. Ministerio de Educación y Ciencia, Servicio Nacional de Información Artística, Madrid.

Gorges, J.G., 1979. Les villas Hispano-romaines. Inventarie et problématique archéologiques. París.

Gorges, J.G., Cerrillo, E., Nogales Basarrate, T. (eds.), 2004. V Mesa Redonda Internacional Lvsitania Romana: Las Comunicaciones. Ministerio de Cultura, Madrid.

López Monteagudo, G., Navarro Sáez, R., De Palol Salellas, P., 1998. Mosaicos romanos de Burgos. Madrid.

Maluquer de Montes, J., 1956. Carta Arqueológica de España. Salamanca. Diputación Provincial de Salamanca, Servicio de Investigaciones Arqueológicas, Salamanca.

Marín Díaz, P., 2011. Una aproximación a la musivaria tardoantigua en liberis. Los mosaicos de la villa de los Vergeles (Granada). Arqueología y Territorio 8, 173-186.

Martín Chamoso, C., 2007. Memoria técnica de la excavación. Villa romana de Saelices el Chico, Salamanca. Informe inédito. Biblioteca del Museo de Salamanca.

Martín Chamoso, C., Hernández Hernández, A.B., 1997. Informe técnico de la excavación arqueológica de la villa romana de Sahelices el Chico, Salamanca. Informe inédito. Biblioteca del Museo de Salamanca.

Molina, J., 2015. Poblamiento rural en el Territorium de Ilici: La granja romana del Cabezo- Clot de Galvany (Elx, Alacant). Sagvntvm 47, 105-120.

Morán, C., 1946. Reseña histórico artística de la provincia de Salamanca. Universidad de Salamanca.

Neira, M.L., Mañanes, T., 1998. Mosaicos romanos de Valladolid. Madrid.

Núñez, J., Sáenz, P., 2005. Una Mutatio de la vía Ab Asturica Burdigalam en Mariturri (Vitoria/Álava). Archivo Español de Arqueología 78, 189-207.

Núñez, J., Saiz, S., 2009. Mariturri. Intervención arqueológica en un tramo de la vía Ab Asturica Burdigalam. In: Santos Yanguas, J. (Ed.), Los Tiempos Antiguos en los Territorios Pirenaicos, 139-158. Universidad del País Vasco, Vitoria-Gasteiz.

Pérez de Dios, V., 2014. El poblamiento romano y tardoantiguo en el Sureste de la provincia de Salamanca. Trabajo de Fin de Máster UNED (Inédito). Salamanca.

Pérez Gómez, P.L., 2007. Excavación de un tramo de la Vía de la Plata en Puerto de Béjar (Salamanca). In: Gillani, G., Santonja, M. (coord.), Arqueología en la Vía de la Plata (Salamanca), 33-42. Béjar (Salamanca).

Pérez Losada, F., 1996. Hacia una definición de los asentamientos rurales en la Gallaecia: poblados (vici) y casas de campo (villae). In: Fernandez Ochoa, C. (Coord.), Los finisterres atlánticos en la antigüedad: época prerromana y romana (Coloquio internacional): homenaje a Manuel Fernández Miranda, 189-200.

Pérez Losada, F., 2002. Entre a Cidade e a Aldea: estudio arqueohistórico dos "aglomerados secundarios" romanos en Galicia. Brigantium: Boletín do Museu Arqueolóxico e Histórico da Coruña 13, 15-348.

Pérez Olmedo, E, Regueras Grande, F., Martín Chamoso, C., Hernández Hernández, A., 1997. Arquitectura romana tardía en la provincia de Salamanca: el complejo de Sahelices el Chico. Boletín del Seminario de Estudios de Arte y Arqueología 63, 179-201.

Regueras, F., Pérez Olmedo, E., 1997. Mosaicos romanos de la Provincia de Salamanca.Salamanca.
Reis, M.P., 2004. Las termas y balnea romanos de Lusitania. Madrid.

Roldán, J.M., 1971. Iter ad Emerita Asturicam: El camino de la Plata. Universidad de Salamanca.

Roldán, J.M., 1998. La conquista romana. In: Salinas, M. (coord.), Historia de Salamanca I. Prehistoria y Edad Antigua. 219-276. Centro de Estudios Salamantinos.

Riz del Árbol Moro, M., Sánchez-Palencia Ramos, F.J., 1999. La minería aurífera romana en el Noroeste de Lusitania: las Cavenes de El Cabaco (Salamanca). Archivo Español de Arqueología 72, 119-139.

Ruiz del Árbol Moro, M., Sánchez-Palencia Ramos, F.J., López Jiménez, O., 2001. La investigación de paisajes culturales y su valoración como zonas arqueológicas: la zona arqueológica de Las Cavenes (El Cabaco, Salamanca). Arqueoweb: Revista sobre Arqueología en Internet 3(1).

Salvador Velaso, M., Viñé Escarpín, A.l., 2007. Excavación arqueológica de la Calzada de la Plata en su avance por el Prado de El Zurguén (Salamanca). In: Gillani, G., Santonja, M. (coord.), Arqueología en la Vía de la Plata (Salamanca), 73-80. Béjar (Salamanca).

Sánchez-Palencia Ramos, F.J., Ruiz del Árbol Moro, M., 2000. Estructuras agrarias y explotación minera en Lusitania nororiental: la Zona Arqueológica de Las Cavenes" (El Cabaco, Salamanca). In: Gorges, J.G., Nogales Basarrate, T. (Coord.), Sociedad y cultura en Lusitania romana. IV Mesa Redonda Internacional, 343-358. Editora Regional de Extremadura, Mérida.

Sarasola Echegoyen, N., 2006. Arqueología en la Construcción de la A-66 "Autovía de la Plata". Extremadura Arqueológica X. Junta de Extremadura, Mérida.

De Soto García, M.R., 2015. El Valle del Río Almar entre la II Edad del Hierro y la Alta Edad Media. Estudio de un microespacio en la Meseta Norte. Tesis Doctoral (inédita). Universidad de Salamanca.

STRATO, 2003. Informe técnico. Trabajos de excavación arqueológica integrados en el proyecto de la Red de Riego para la mejora y modernización del regadío de la comunidad de regantes "Vegas del Almar". Términos municipales de Alconada, Coca de Alba, Garcihernández, Peñarandilla y Ventosa del Río Almar (Salamanca). Informe inédito. Biblioteca del Museo de Salamanca, Salamanca. 
